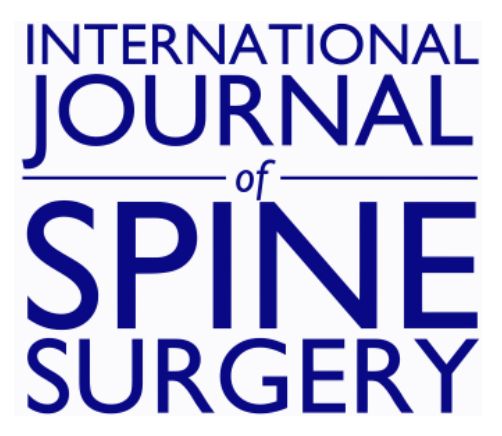

\title{
Early Complications in Vertical Expandable Prosthetic Titanium Rib and Magnetically Controlled Growing Rods to Manage Early Onset Scoliosis
}

Alejandro Peiro-Garcia, Jonathan Bourget-Murray, Isadora Suarez-Lorenzo, Fabio Ferri-De-Barros and David Parsons

Int J Spine Surg 2021, 15 (2) 368-375

doi: https://doi.org/10.14444/8048

http://ijssurgery.com/content/15/2/368

This information is current as of April 26, 2023.

Email Alerts Receive free email-alerts when new articles cite this article. Sign up at:

http://ijssurgery.com/alerts

The International Journal of Spine Surgery

2397 Waterbury Circle, Suite 1,

Aurora, IL 60504, Phone: +1-630-375-1432 


\title{
Early Complications in Vertical Expandable Prosthetic Titanium Rib and Magnetically Controlled Growing Rods to Manage Early Onset Scoliosis
}

\author{
ALEJANDRO PEIRO-GARCIA, MD,${ }^{1}$ JONATHAN BOURGET-MURRAY, MD, $\mathrm{CM},{ }^{2,3}$ ISADORA SUAREZ- \\ LORENZO, MD ${ }^{4}$ FABIO FERRI-DE-BARROS, MD, MSc, FSBOT, FRCSC, ${ }^{2,3}$ DAVID PARSONS, MD, \\ $\mathrm{FRCSC}^{2,3}$ \\ ${ }^{I}$ Spine Unit, Division of Pediatric Orthopedic Surgery, Hospital Sant Joan de Déu, Universitat de Barcelona, Esplugues de Llobregat, Barcelona, Spain, ${ }^{2}$ Cumming \\ School of Medicine, University of Calgary, Calgary, Alberta, Canada, ${ }^{3}$ Department of Surgery, Division of Pediatric Orthopedic Surgery, Alberta Children's \\ Hospital, Calgary, Alberta, Canada, ${ }^{4}$ Universidad de Las Palmas de Gran Canaria, Las Palmas de Gran Canaria, Spain
}

\begin{abstract}
Objectives: The aim of this study is to examine whether surgical treatment of early onset scoliosis (EOS) with magnetically controlled growing rods (MCGRs) or a vertical expandable prosthetic titanium rib (VEPTR) resulted in fewer short-term (24 months) complications and reoperations.

Background: EOS is a challenging problem for spine surgeons that has been managed with different growthfriendly instrumentation systems. Although rib-based devices encourage spinal growth via regular lengthening, the high rate of complications and reoperations leads us to use spine-based devices such as MCGRs to mitigate this concern.

Methods: A total of 35 EOS patients were included in the study. Twenty patients were included in the VEPTR group, and 15 patients were included in the MCGR group. Demographic data and 2 years of postoperative complications and reoperations were reviewed retrospectively. As secondary outcomes, radiographic outcomes were reported preoperatively and 1 year after surgery. Indications for this technique and complications were collected from the charts.

Results: Demographic data showed no significant differences between the 2 groups. Significant differences were found in the complications rate at 2 years, with $65 \%$ complications in the VEPTR group and $13.3 \%$ complications in the MCGR group $(P<.001)$. The reoperation rate at 2 years was also significantly higher in the VEPTR group, with $50 \%$ versus $13.3 \%$ in the MCGR group $(P=.0009)$. As secondary outcomes, radiological parameters such as main curve Cobb angle correction $(P=.001)$ and apical vertebral translation $(P=.002)$ were significantly higher in the MCGR group. Significant differences were also found in sagittal profile parameters; T1-T12 and T1-S1 were significantly higher in the MCGR group $(P<.001)$.
\end{abstract}

Conclusions: According to our results, VEPTR has significantly higher complication and reoperation rates at 2 years postsurgery compared with MCGR.

Level of Evidence: 4.

Other \& Special Categories

Keywords: early onset scoliosis, growth friendly, non-fusion, VEPTR, MCGR, complications

\section{INTRODUCTION}

The natural history of early-onset scoliosis (EOS) is variable and highly influenced by the underlying etiology of the scoliosis. It is important to consider the unique features of this natural history, because frequently these skeletally immature patients present with spinal deformities that threaten their pulmonary function and ultimately risk early death. ${ }^{1-3}$ Many surgical treatment options have been described in the literature. ${ }^{4-6}$ Choosing the appropriate treatment strategy depends on the patient's symptoms, patient's age, underlying diagnosis, magnitude of spinal deformity, and the preferences of the surgeon and the patient's family.

Spine surgery in patients with EOS aims to correct the spine deformity while allowing for future growth and improvement of respiratory function, therefore improving the patients' long-term, healthrelated quality of life. To that end, avoiding multiple surgeries and general anesthetics is paramount. ${ }^{7}$

Growing rods have been shown to be a reliable surgical strategy to manage EOS. ${ }^{7-10}$ Traditional growing rods (TGR) and a vertical expandable 
prosthetic titanium rib (VEPTR) require routine surgical lengthening during a child's development. Unplanned revision surgeries for managing complications of these systems are also common, regardless of the fixation technique used. ${ }^{11}$ These come with hefty costs, given the required health-resource use and the added psychological impact for both the patients and their families. The complication rate of growing rods is reported to range from $20 \%-$ $72 \% .^{11-18}$ Repeated general anesthetics and surgeries adversely affect health outcomes in children and may result in psychological and financial distress for their parents and caregivers. ${ }^{19,20}$

Magnetically controlled growing rods (MCGR) offer a promising alternative to treating these skeletally immature patients. This technology comes with the added benefit of minimizing repetitive surgical sessions for the rods to be lengthened. The MCGRs are designed with noninvasive lengthening technology by virtue of a magnetically driven actuator. Recent studies have shown similar clinical outcomes between MCGRs and TGR systems. ${ }^{21,22}$ Although the number of planned invasive surgeries to lengthen is reduced, there continues to be complications related to instrumentation. ${ }^{23}$

Following the publication from the National Institute for Health and Care Excellence (NICE) study, the pediatric spine surgeons at our academic center began using MCGRs more frequently to manage EOS. Given the scarcity of high-quality literature comparing the clinical outcomes of VEPTR and MCGR for the treatment of EOS, short-term complications and reoperation rates have yet to be elucidated.

The aim of this study is to examine whether surgical treatment of EOS with MCGRs or VEPTR resulted in fewer short-term (24 months) complications and reoperations.

\section{METHODS}

\section{Study Design}

This is a retrospective, single-center cohort study. In accordance with our institute's ethical standards, we reviewed the medical records of 35 consecutive patients who underwent spine instrumentation with either VEPTR or MCGs for the management of EOS between 2010 and 2016. Patients were identified from the surgical booking office of the 2 senior authors (D.P. and F.D.B..), both of whom are fellowship-trained pediatric spine surgeons. Indica- tions for surgery were the same in both groups. Those meeting the following criteria were included in the study: (1) have EOS of any etiology, (2) have no history of previous spine surgery, (3) have no history of systemic disease(s) or primary chest-wall deformity, (4) must have exhausted nonoperative treatment, (5) have a progressive spinal deformity of $>10^{\circ}$ over a 6 -month period or a major curve Cobb angle greater than or equal to $40^{\circ}$, and (6) have completed a minimum of 2 years clinical follow-up.

Two cohorts were defined on the basis of the surgical system used intraoperatively: VEPTR (DePuy Synthes, Raynham, Massachusetts) or MCGR (MAGEC system, NuVasive, San Diego, California). Twenty patients were included in the VEPTR cohort, and 15 patients were included in the MCGR cohort. Following the publication of the NICE study in 2014, the pediatric spine surgeons at our academic center began using MCGRs to manage EOS. Therefore, all VEPTR patients reported in this study had their index surgery prior to this change in practice.

\section{Operative Technique}

All patients within each group underwent a comparable operative procedure and postoperative rehabilitation protocol. All patients received a similar anesthetic, targeting a normotensive anesthetic. Motor-evoked potentials (MEPs) and somatosensory evoked potentials (SSEPs) were captured with an XLTEK Protector 16 Channel IOM (Natus Medical Inc, Oakville, Canada) and interpreted by a trained specialist. Warning criteria for MEPs and SSEPs were a decrease in signal amplitude beyond $30 \%$ and $50 \%$, respectively, a change in MEP signal morphology, or a $10 \%$ increase in SSEP signal latency.

Eleven patients in the MCGR cohort underwent staged procedures for insertion of MCGRs. These patients first underwent preimplantation of thoracic and lumbar anchors. Proximal anchor strategy for this group was pedicle and transverse process hooks in claw conformation (6 if feasible) and pedicle screws in the lumbar spine. The spinous processes of the respective levels were used for autograft. Temporary short rods were inserted to maintain spine alignment until the definitive second-stage procedure was performed. Seven of these patients were placed in constant halo-gravity traction between their staged procedures as per the clinical judgment of the surgeon. This was performed to 
optimize anchor-bone fusion to reduce risk of subsequent anchor dislodgement. Five pounds of traction was started immediately following surgery and increased by $1 \mathrm{lb} / \mathrm{d}$ until $50 \%$ of the child's body weight $(\mathrm{kg})$ was reached. For the second procedure, temporary rods were removed and MCGRs and a cross-link were inserted. Rod lengthening was performed in the clinic every 3 months (aiming for $3 \mathrm{~mm}$ ), with a median of 6 in 2 years.

All 20 patients treated with VEPTR were planned for single-stage instrumentation. However, 2 patients had staged implant insertion due to intraoperative complications. All surgeries were performed in similar fashion. Lengthening was performed every 6-9 months (depending on medical conditions) in the operating room, with a median of 4 in 2 years.

\section{Outcome Measures}

Primary outcome measures were short-term (24 months) complications related to surgery (eg, surgical site infection, implant failure, spinal curve progression, intraoperative pneumothorax, neurological injury) and complications requiring revision surgery within the first year of the index surgery.

Radiographic parameters reported relate to spinal deformity correction. These include changes in coronal and sagittal balance as well as thoracic kyphosis and lumbar lordosis between the immediate preoperative standing radiographs and the postoperative standing radiographs (or sitting for nonambulatory patients) obtained at the 2-year follow-up. In addition, thoracic and lumbar curve angles, coronal balance, sagittal balance, apical vertebral translation (AVT), T1 tilt, and T1-T12 and T1-S1 heights were measured.

\section{Statistical Analysis}

All statistical tests were done using $\mathrm{R}$ Project (version 1.0.153, https://www.R-project.org/). Median values and interquartile range (IQR) between groups were compared using MannWhitney test for quantitative variables nonnormally distributed, whereas the Fisher test and $\chi^{2}$ test were used for qualitative variables. $P$ value of less than .05 was considered statistically significant.

\section{RESULTS}

Of the 35 patients included for analysis, 2 cohorts were defined: 20 patients were included in the VEPTR cohort and 15 patients were included in
Table 1. Patient characteristics and demographics.

\begin{tabular}{lccr}
\hline Characteristic & $\begin{array}{c}\text { MCGR Cohort } \\
(\mathbf{n}=\mathbf{1 5})\end{array}$ & $\begin{array}{c}\text { VEPTR Cohort } \\
(\mathbf{n}=\mathbf{2 0 )}\end{array}$ & $\boldsymbol{P}$ Value \\
\hline Male sex, n (\%) & $8(53.3)$ & $9(45)$ & .884 \\
Age, median (IQR) y & $7(3,10)$ & $4(1.6,12)$ & $.020^{\mathrm{a}}$ \\
Stage 1, n (\%) & $4(26.7)$ & $18(90)$ & $<.001^{\mathrm{a}}$ \\
Stage 2, n (\%) & $11(73.3)$ & $2(10)$ & \\
Etiology, n (\%) & & & \\
$\quad$ Neuromuscular & $9(60)$ & $3(15)$ & \\
$\quad$ Congenital & $3(20)$ & $1(5)$ & \\
$\quad$ Idiopathic & $1(6.7)$ & $5(25)$ & \\
Syndromic & $2(13)$ & & \\
\hline
\end{tabular}

Abbreviations: IQR, interquartile range; MCGR, magnetically controlled growing rod; VEPTR, vertical expandable prosthetic titanium rib.

${ }^{\mathrm{a}}$ Denotes statistical significance.

the MCGR cohort. All baseline patient characteristics are presented in Table 1. The median age of patients in the MCGR cohort was older than that of patients in the VEPTR cohort $(P=.02)$. There was no statistical difference with regards to the underlying ethology (eg, neuromuscular, congenital, idiopathic, or syndromic scoliosis) for the patient's EOS across groups $(P=.891)$.

\section{Primary Outcomes}

At the 2-year follow-up, the total complication rate was significantly higher in the VEPTR cohort compared with the MCGR cohort, 65\% versus $13.3 \%$, respectively (VEPTR, $13 / 20$ patients; MCGR, $2 / 15$ patient; $P<.001$ ). Sixteen complications in 13 patients were recorded in the VEPTR cohort; whereas, in the MCGR cohort only 3 complications were reported in 2 patients. All primary outcome measures are shown in Table 2.

No significant differences were found in infection rates between the VEPTR (10\%) and MCGR cohorts, with $10 \%$ and $6.7 \%$, respectively (VEPTR, 2/20 patients; MCGR, $1 / 15$ patient; $P=.727$ ). Implant failures requiring surgery within 1 year of index surgery were significantly higher in the VEPTR group (VEPTR, 7/20, 35\%; MCGR, 2/15, $13.3 \% ; P=.048)$. In the VEPTR cohort, 5 patients had a proximal anchor dislodgement or migration, 1 patient had a pelvic cradle migration to the pelvis, and 1 patient had a pelvic cradle breakage. Five patients required a new rod insertion in less than a year due to curve progression or needed a new rod because the previous one was fully expanded $(P=$ .036). One patient with a unilateral rod required a new contralateral VEPTR insertion in less than a year due to curve progression. Three patients had intraoperative pneumothorax during VEPTR insertion requiring intraoperative chest tube insertion; 1 
Table 2. Complication and reoperation rates. ${ }^{a}$

\begin{tabular}{lccc}
\hline & MCGR $(\mathbf{n}=\mathbf{1 5})$ & VEPTR $(\mathbf{n}=\mathbf{2 0})$ & $\boldsymbol{P}$ Value \\
\hline Complications, n (\%) & & & \\
$\quad$ Infection & $1(6.7)$ & $2(10)$ & .727 \\
Implant failure & $2(13.3)$ & $7(35)$ & .048 \\
Progression & 0 & $1(5)$ & .380 \\
New rod (<1 y) & 0 & $5(25)$ & .036 \\
Pneumothorax (1x) & 0 & $3(15)$ & .066 \\
Pneumothorax (2x) & 0 & $1(5)$ & \\
Neurological injury & 0 & $1(5)$ & .380 \\
No. of patients & $2(13.3)$ & $13(65)$ & \\
Total complications & 3 & 16 & $<.001$ \\
Reoperation Rate & & & \\
Reoperation (1x) & 1 & 8 & .006 \\
Reoperation (2x) & 1 & 2 & \\
Reoperation (4x) & 0 & 1 & \\
No. of patients, $\mathrm{n}(\%)$ & $2(13.3)$ & $10(50)$ & \\
Total reoperations & 3 & 16 & \\
\hline
\end{tabular}

Abbreviations: MCGR, magnetically controlled growing rod; VEPTR, vertical expandable prosthetic titanium rib.

${ }^{a}$ Implant failure: includes dislodgements, migrations, and breakage. Progression: spine deformity progression requiring new rod insertion. Newrodly: new rod inserted in less than 1 year. Pneumothorax (1x): patients with 1 pneumothorax. Pneumothorax (2x): 2 separate pneumothorax in same patient in less than 1 year. Reoperation (1x): patients with 1 reoperation in less than 1 year from index surgery. Reoperation $(2 \mathrm{x})$ : patients requiring 2 reoperations in less than 1 year from index surgery. Reoperation (5x): patients requiring 5 reoperations in less than one year from index surgery

patient had a pneumothorax during the VEPTR rod insertion and a subsequent pneumothorax during a separate lengthening, requiring (like the other 3 patients) a chest tube. One VEPTR patient had a permanent neurologic injury in the immediate postoperative period due to spinal cord ischemia despite the lack of monitoring changes during surgery.

It is, therefore, not surprising that reoperation rates were found to be significantly higher in the VEPTR group (VEPTR, 10/20 patients, 50\%; MCGR, $2 / 15,13.3 \% ; P=.006)$. Sixteen unplanned surgeries were performed on 10 patients in the VEPTR cohort, whereas 2 patients in the MCGR cohort underwent 3 unplanned surgeries.

In addition to the 7 implant failures aforementioned, 2 patients treated with VEPTR rods suffered wound infections. One patient required 4 surgical debridements, whereas the other was successfully managed with 1 surgical debridement. The patient who suffered a neurologic injury had her rods removed on postoperative day 1 and would subsequently have new VEPTR rods inserted 1 month later without any further complications. One patient with an intraoperative pneumothorax required a staged surgery to put the second VEPTR. One patient with unilateral VEPTR required a new contralateral rod due to curve progression.

Two patients treated with a single-stage MCGR system required unplanned surgeries $(13.3 \%)$ in the
Table 3. Preoperative radiographic measurements.

\begin{tabular}{|c|c|c|c|}
\hline Characteristic $^{\mathrm{a}}$ & $\begin{array}{c}\text { MCGR Group } \\
(\mathbf{n}=15)\end{array}$ & $\begin{array}{l}\text { VEPTR Group } \\
(\mathbf{n}=\mathbf{2 0})\end{array}$ & $P$ Value \\
\hline Thoracic curve angle, ${ }^{\circ}$ & $68(40,129)$ & $75(18,126)$ & .607 \\
\hline Lumbar curve angle, ${ }^{\circ}$ & $60(45,76)$ & $58.5(15,78)$ & .945 \\
\hline $\mathrm{AVT}, \mathrm{mm}$ & $41(25,105)$ & $45(4,129)$ & .521 \\
\hline T1 tilt, ${ }^{\circ}$ & $17(1,32)$ & $12(0,39)$ & .781 \\
\hline T1-T12 height, mm & $173(105,276)$ & $150(87,199)$ & $.034^{\mathrm{b}}$ \\
\hline T1S1-Pre & $289(194,432)$ & $257(164,296)$ & $.033^{\mathrm{b}}$ \\
\hline Coronal balance, $\mathrm{mm}$ & $22(0,60)$ & $15(0,32)$ & .102 \\
\hline Thoracic kyphosis, $^{\circ}$ & $32(4,96)$ & $42(-42,96)$ & .515 \\
\hline T2-T5 kyphosis, ${ }^{\circ}$ & $13(-10,50)$ & $6(-24,23)$ & .051 \\
\hline Lumbar lordosis, $^{\circ}$ & $51(19,104)$ & $44.5(-26,59)$ & .225 \\
\hline Sagittal balance, $\mathrm{mm}$ & $29(-37,138)$ & $49(0,78)$ & .219 \\
\hline
\end{tabular}

year that followed their index surgeries. The first was due to implant dislodgement at 8-months postoperation, requiring a revision of 1 of the cephalic implants followed by a wound infection requiring 1 surgical debridement. A second patient with Proteus syndrome had an unplanned surgery due to a broken rod.

\section{Secondary Outcomes}

Preoperative radiographic measurements (Table 3) showed significant differences between cohorts for T1-T12 height (VEPTR, $150 \mathrm{~mm}$ [87, 199]; MCGR, $173 \mathrm{~mm}[105,276] ; P=.0343)$, and T1-S1 height (VEPTR, $257 \mathrm{~mm}$ [164, 296]; MCGR 289 $\mathrm{mm}[194,432] ; P=.0328)$. This effect can be explained by the younger median age of patients in the VEPTR cohort. No other significant differences were found in the preoperative measurements.

Postoperative radiographic measurements and deformity correction parameters are presented in Tables 4 and 5. Postoperative thoracic curve angle was significantly smaller in the MCGR group compared with the VEPTR group (VEPTR; 53.5 [15, 69]; MCGR, 42 $[12,59] ; P=.0295)$. The percentage of main curve angle correction with surgery was significantly higher in the MCGR group (VEPTR, 20 ${ }^{\circ}$ [-15.2, 58]; MCGR, 47.2 $[13,59.7] ; P$ $=.0138)$. The AVT correction was significantly higher in the MCGR group, with a median of 18 $\mathrm{mm}(1,50)$, whereas the median correction in the VEPTR group was $6 \mathrm{~mm}(-8,64 ; P=.0263)$. Postoperative T1-T12 and T1-S1 heights were significantly higher in the MCGR cohort, with a median T1-T12 of $207 \mathrm{~mm}(136,295)$ and median T1-S1 of $336 \mathrm{~mm}(228,471)$, compared with a 
Table 4. Secondary outcomes: postoperative measurements.

\begin{tabular}{lccc}
\hline Characteristic $^{\mathbf{a}}$ & $\begin{array}{c}\text { MCGR Group } \\
(\mathbf{n}=\mathbf{1 5})\end{array}$ & $\begin{array}{c}\text { VEPTR Group } \\
(\mathbf{n}=\mathbf{2 0})\end{array}$ & $\boldsymbol{P}$ Value \\
\hline Thoracic curve angle, $^{\circ}$ & $42(12,59)$ & $53.5(15,69)$ & $.030^{\mathrm{b}}$ \\
Lumbar curve, $^{\circ}$ & $35(20,64)$ & $37.5(12,68)$ & 1 \\
AVT, mm $^{\circ}$ & $21(9,85)$ & $33(0,92)$ & .69 \\
T1 Tilt, $^{\circ}$ & $8(1,26)$ & $11.5(0.4,36)$ & .174 \\
T1-T12 height, mm & $207(136,295)$ & $167(95,228)$ & $.017^{\mathrm{b}}$ \\
T1-S1-Post $_{\text {Coronal balance, mm }}$ & $336(228,471)$ & $273(183,371)$ & $.007^{\mathrm{b}}$ \\
Thoracic kyphosis, $^{\circ}$ & $19(0,81)$ & $15(0,47)$ & .741 \\
T2-T5 kyphosis, $^{\circ}$ & $21(7,47)$ & $33(-7,97)$ & .0762 \\
Lumbar lordosis, $^{\circ}$ & $9(-18,35)$ & $10(-12,30)$ & .85 \\
Sagittal balance, mm $^{\circ}$ & $35(20,64)$ & $37.5(12,68)$ & 1 \\
& $16(-39,112)$ & $39.5(-15,47.5)$ & .163
\end{tabular}

Abbreviations: AVT, apical vertebral translation; MCGR, magnetically controlled growing rod; Post, postoperative; VEPTR, vertical expandable prosthetic titanium rib.

${ }^{a}$ The values are given as the median with the interquartile range in parentheses. ${ }^{\mathrm{b}}$ Denotes statistical significance.

median T1-T12 height of $167 \mathrm{~mm}(95,228 ; P=$ $.0174)$ and median T1-S1 height of $273 \mathrm{~mm}$ (183, $371 ; P=.00647)$ in the VEPTR group. However, direct comparison of preoperative and postoperative T1-T12 and T1-S1 heights at the 2-year postoperative follow-up showed no statistical difference.

\section{DISCUSSION}

During the last decades, multiple growing rod systems have been described. Traditionally, growing rods required routine surgical lengthening, which was associated with their high complication rates. ${ }^{7}$ In the same vein, rib-based constructs required multiple surgical lengthening. A French series ${ }^{24}$ of 54 VEPTRs with a mean follow-up of 22.5 months reported a complication rate of $137 \%$ per patient and $40 \%$ per surgery. In our study, only 16 complications were found in 12 patients $(65 \%)$. Nonetheless, our study only reports the short-term complications during the first 2 years after rod insertion. Hook migration is the most common complication associated with VEPTR surgery. ${ }^{25-28}$ It is expected to have higher thorax complications such pneumothorax in the VEPTR, because this is a rib-based implant; whereas, in our case, MCGR proximal anchors were spine based. Infection is also a common complication in VEPTR patients. Smith and $\mathrm{Smith}^{29}$ reported an infection rate of $19.6 \%$ per patient and $2.8 \%$ per surgery. In our series, during the first 2 years after the rod insertion, only 2 patients had a wound infection $(10 \%)$; however, the risk of infection increases with the number of lengthening surgeries. Previous studies have reported neurological complications in $6.6 \%$ of patients, ${ }^{30-33}$ including brachial plexus injury (2.6\%), Horner syndrome $(0.7 \%)$, lower extremity neurological injury $(1.2 \%)$, pain, or neurological deficit in unspecified territory $(2.1 \%)$. In our series, only 1 patient treated with VEPTR suffered postoperative neurological injury $(6.7 \%)$ due to spine ischemia.

To mitigate the high rate of complications reported with TGRs and VEPTR systems, MCGRs were designed for nonoperative lengthening of the rods with a magnetically driven actuator with clinical outcomes similar to those of TGR systems. $^{21-22}$ In a meta-analysis performed by the NICE in the United Kingdom, the authors concluded that using the MAGEC system would avoid repeated surgical procedures for growing rod lengthening. ${ }^{22}$ This could reduce complications and have other physical and psychological benefits for affected children and their families.

However, a high rate of unplanned revisions is still concerning. Choi et $\mathrm{al}^{34}$ described a complication rate of $42 \%$ in 54 patients with $28 \%$ of reoperations. The authors reported 6 broken rods, $2(33 \%)$ of which failed early (4 months). Seven patients $(13 \%)$ had either proximal or distal implant-related complications at an average of 8.4

Table 5. Secondary outcomes: radiographic correction.

\begin{tabular}{|c|c|c|c|}
\hline Characteristics $^{\mathbf{a}}$ & MCGR Group $(n=15)$ & VEPTR Group $(n=20)$ & $P$ Value \\
\hline Thoracic curve angle correction, ${ }^{\circ}$ & $34(9,77)$ & $15(-5,63)$ & $.050^{\mathrm{b}}$ \\
\hline Lumbar curve angle correction, ${ }^{\circ}$ & $47.2(13,59.7)$ & $20(-15.2,58)$ & $.014^{\mathrm{b}}$ \\
\hline AVT correction, $\mathrm{mm}$ & $18(1,50)$ & $6(-8,64)$ & $.026^{\mathrm{b}}$ \\
\hline $\mathrm{T} 1$ tilt correction, ${ }^{\circ}$ & $3(-11,23)$ & $0(-4,4.5)$ & .174 \\
\hline T1-T12 height difference, $\mathrm{mm}$ & $27(2,61)$ & $21(-10,62)$ & .639 \\
\hline T1-S1 height difference, $\mathrm{mm}$ & $39(10,88)$ & $28(-40,75)$ & .0768 \\
\hline Coronal balance correction, $\mathrm{mm}$ & $0(-21,37)$ & $-2(-21,22)$ & .404 \\
\hline Thoracic kyphosis correction, ${ }^{\circ}$ & $5(-15,74)$ & $5(-35,25)$ & .329 \\
\hline T2-T5 kyphosis correction, ${ }^{\circ}$ & $-2(-18,68)$ & $-5(-30,9)$ & .48 \\
\hline Lumbar lordosis correction, ${ }^{\circ}$ & $2(-21,50)$ & $0.5(-39,30)$ & .503 \\
\hline Sagittal balance correction, ${ }^{\circ}$ & $2(-68,166)$ & $15.5(-40,78)$ & .814 \\
\hline
\end{tabular}

Abbreviations: AVT, apical vertebral translation; MCGR, magnetically controlled growing rod; VEPTR, vertical expandable prosthetic titanium rib.

${ }^{\mathrm{a}}$ The values are given as the median with the interquartile range in parentheses.

${ }^{\mathrm{b}}$ Denotes statistical significance. 
months. Two infections were reported during the first year. ${ }^{34}$ Kwan et $\mathrm{al}^{23}$ reported an unplanned reoperation rate of $46.7 \%$ (14 unplanned surgeries) in 30 patients managed with MCGR, with a mean follow-up of 36 months. Three reoperations happened during the first year. Ridderbusch et $\mathrm{al}^{35}$ reported 5 implant failures requiring revision surgery in a series of 24 patients $(20 \%)$, but the authors did not report at what point during followup the mechanical failures occurred. In a multicenter study, Lebon et $\mathrm{al}^{36}$ reported 24 complications and 13 reoperations in 30 patients $(43 \%)$; however, it is again not clear when during follow-up these complications occurred. Teoh et $\mathrm{al}^{37}$ presented 6 revision surgeries in 14 patients $(43 \%)$, which occurred during 17-46 months of follow-up. In our series, the reoperation rate at the 2-year postoperative follow-up in the MCGR group was much lower-2 reoperations in 1 patient $(6.7 \%)$ due to a wound infection requiring surgical debridement soon after the index surgery and proximal implant dislodgement at 8 months postinsertion requiring reinstrumentation. This low rate of implant complications in our MCGR cohort compared with the literature may be largely explained by the surgical technique used in 11 of 15 patients $(73 \%)$. As described above, 11 patients underwent a staged MCGR insertion with preimplantation of the anchor points and subsequent insertion of the MCGR 8-12 weeks later with or without a period of halo-gravity traction. This approach may reduce the benefit of lower reoperation rates in the MCGR group; however, this aims to favor good anchorbone fusion and, thus, reduces risk of anchors dislodgement during the insertion of the MCGR in patients with poor bone density, stiff curves, or hyperkyphosis. ${ }^{43}$ In addition, halo-gravity traction has the added benefit of partially correcting the spinal deformity, facilitating appropriate placement of the actuators to ensure optimal rod function. The use of preoperative halo-gravity traction in 11 patients in the MCGR group could explain the higher percentage of main curve angle and AVT correction in our series.

There are few studies, to the best of our knowledge, comparing complication rates following TGRs to VEPTR for the surgical treatment of EOS. Lebon et $\mathrm{al}^{36}$ recently showed that using MCGR, an average of 2.03 scheduled surgical procedures per patient could be avoided compared with patients treated with TGRs.
In our study, there was no gradual loss of effectiveness over the course of the first 2 years. The so-called law of diminishing returns described with growing rods seemed applicable to MCGR from the fourth distraction session onward. ${ }^{38}$ The phenomenon was first reported by Sankar et $\mathrm{al}^{38}$ and represented the gradual decrease in length gain with each subsequent lengthening, despite an increased distraction force applied. ${ }^{39}$ This loss of lengthening could be associated with residual tissue stiffness that may be diminishing with subsequent spinal growth. Yet this may also be partially explained by technical issues and related to the improper placement of the controller above the MCGR actuator. ${ }^{40}$ This may explain the low rate of implant complications at 2 years in the MCGR group because our MCGR cohort had a median of 8 distractions in 2 years. Different lengthening protocols in both groups (3 months in the MCGR group and 6-9 months in the VEPTR group) could influence the complication rate. Finally, different biomechanics of these implants and proximal anchor strategy (4-6 hooks in the MCGR group and 2 rib anchors in the VEPTR group) could have significant impact on the complication rate. This is a controversial topic in EOS meetings; however, it is difficult to make conclusions due to the lack of biomechanical studies comparing different growthfriendly implants and proximal anchor strategies.

One of the MCGR limitations is the implant: The actuator is straight and not bendable, making ideal sagittal alignment not possible in some patients. Whereas VEPTR can be used in smaller patients (our VEPTR cohort is younger than the MCGR cohort) because the implant has no actuator, MCGRs are sometimes difficult to use in younger patients because they need to put the actuator in a straight part of the spine that cannot be bent. In the same vein, staged surgery with preoperative halogravity is particularly useful for correction of thoracic kyphotic deformity and for patients whose pulmonary and nutritional status are suboptimal, as described previously by Johnston. ${ }^{43}$ This strategy is also helpful in patients with a short trunk to gain enough time to fit the actuator in a straighter spine. Although costs are not analyzed in this work, it is important to mention that this strategy could increase costs per case because it increases hospital stay.

Limitations of this study include its retrospective nature, the small sample size, and the fact that this is 
a single-center study; this may limit our conclusions. One of the challenges in designing studies in EOS that allow for meaningful comparisons of surgical processes and outcomes is the heterogeneity of this patient population, ${ }^{41,42}$ which may also affect our results. In our study, no significant differences were found in etiology, and the same indications for surgery were used in both groups. Another limitation is the relatively short follow-up. Despite the reported increase in complications of growthfriendly procedures with increased follow-up, the purpose of this study was to compare the early complications rate (2 years) for patients with EOS managed with VEPTR versus MCGR. Finally, the high complication rate in the VEPTR group may suggest that the surgeons were in their learning curve; the surgeons had been using VEPTR since 2004, whereas the surgeons started using MCGR in 2015. The surgeons decided to switch to magnetic growth-friendly devices after promising results in previous studies with MCGR. ${ }^{22}$ Further follow-up is needed to accurately account for long-term complications.

\section{CONCLUSIONS}

Our data suggest that EOS patients managed with MCGR have a lower complication rate and unplanned surgery rate than VEPTR during the first 2 years. The staged approach may explain the low implant complications at 2 years in the MCGR group, and longer-term follow-up is needed to determine whether the benefits persist after 2 years.

\section{REFERENCES}

1. Harrington PR. Treatment of scoliosis: correction and internal fixation by spine instrumentation. June 1962. J Bone Joint Surg Am. 2002;84(2):316. PMID: 11861739.

2. Karol LA, Johnston C, Mladenov K, Schochet P, Walters $\mathrm{P}$, Browne RH. Pulmonary function following early thoracic fusion in non-neuromuscular scoliosis. J Bone Joint Surg Am. 2008;90(6):1272-1281.

3. Moe JH, Kharrat K, Winter RB, Cummine JL. Harrington instrumentation without fusion plus external orthotic support for the treatment of difficult curvature problems in young children. Clin Orthop Relat Res. 1984; $185: 35-45$.

4. Tis JE, Karlin LI, Akbarnia BA, et al. Early onset scoliosis: modern treatment and results. $J$ Pediatr Orthop. 2012;32:647-657.

5. Phillips JH, Knapp DR Jr, Herrera-Soto J. Mortality and morbidity in early-onset scoliosis surgery. Spine. 2013;38:324327.

6. Pehrsson K, Larsson S, Oden A, Nachemson A. Longterm follow-up of patients with untreated scoliosis. A study of mortality, causes of death, and symptoms. Spine. 1992;17:10911096.

7. Thompson GH, Akbarnia BA, Campbell RM Jr. Growing rod techniques in early-onset scoliosis. $J$ Pediatr Orthop. 2007;27:354-361.

8. Marks DS, Iqbal MJ, Thompson AG, Piggott H. Convex spinal epiphysiodesis in the management of progressive infantile idiopathic scoliosis. Spine (Phila Pa 1976). 1996;21(16):18841888. doi:10.1097/00007632-199608150-00010

9. Akbarnia BA, Marks DS, Boachie-Adjei O, Thompson AG, Asher MA. Dual growing rod technique for the treatment of progressive early-onset scoliosis: a multicenter study. Spine. 2005;30:S46-S57.

10. Akbarnia BA, Breakwell LM, Marks DS, et al. Dual growing rod technique followed for three to eleven years until final fusion: the effect of frequency of lengthening. Spine. 2008;33:984-990.

11. Sankar WN, Acevedo DC, Skaggs DL. Study. Comparison of complications among growing spinal implants. Spine. 2010;35:2091-2096.

12. Bess S, Akbarnia BA, Thompson GH, et al. Complications of growing-rod treatment for early-onset scoliosis: analysis of one hundred and forty patients. J Bone Joint Surg Am. 2010;92:2533-2543.

13. Caldas JC, Pais-Ribeiro JL, Carneiro SR. General anesthesia, surgery and hospitalization in children and their effects. Eur Spine J. 2016;25:578-582.

14. Rolton D, Richards J, Nnadi C. Magnetically controlled growing rods versus a conventional growing rod system in the treatment of early onset scoliosis: a cost comparison. Eur Spine J. 2015;24(7):1457-1461.

15. Watanabe K, Uno K, Suzuki T, et al. Risk factors for complications associated with growing-rod surgery for earlyonset scoliosis. Spine. 2013;38(8):E464-E468.

16. Hickey BA, Towriss C, Baxter G, et al. Early experience of MAGEC magnetic growing rods in the treatment of early onset scoliosis. Eur Spine J. 2014;23(1):61-65.

17. Yazici M, Olgun D. Growing rod concepts: state of the art. Eur Spine J. 2013;22(2):118-130.

18. Cheung KMC, Cheung JPY, Samartzis D. Magnetically controlled growing rods for severe spinal curvature in young children: a prospective case series. Lancet. 2012;379:1967-1974.

19. Flick RP, Katusic SK, Colligan RC, et al. Cognitive and behavioral outcomes after early exposure to anesthesia and surgery. Pediatrics. 2011;128(5):e1053-e1061.

20. Ing C, DiMaggio C, Whitehouse A, et al. Long-term differences in language and cognitive function after childhood exposure to anesthesia. Pediatrics. 2012;130(3):e476-e485.

21. Akbarnia BA, Pawelek JB, Cheung KM, et al. Traditional growing rods versus magnetically controlled growing rods for the surgical treatment of early-onset scoliosis: a case-matched 2-year study. Spine Deformity. 2014;2(6):493-497.

22. Jenks M, Craig J, Higgins J, et al. The MAGEC system for spinal lengthening in children with scoliosis: a NICE medical technology guidance. Appl Health Econ Health Policy. 2014;12(6):587-599.

23. Kwan KYH, Alanay A, Yazici M, et al. Unplanned reoperations in magnetically controlled growing rod surgery for early onset scoliosis with a minimum of two-year follow-up. Spine (Phila Pa 1976). 2017;42(24):E1410-E1414. doi:10.1097/ BRS.0000000000002297

24. Lucas G, Bollini G, Jouve JL, et al. Complications in 
pediatric spine surgery using the vertical expandable prosthetic titanium rib, the French experience. Spine (Phila Pa 1976). 2013 Dec 1;38(25):E1589-599. doi:10.1097/BRS. 0000000000000014

25. Hasler CC, Mehrkens A, Hefti F. Efficacy and safety of VEPTR instrumentation for progressive spine deformities in young children without rib fusions. Eur Spine J. 2010;19:400408.

26. Smith JR, Samdani AF, Pahys J, et al. The role of bracing, casting, and vertical expandable prosthetic titanium rib for the treatment of infantile idiopathic scoliosis: a singleinstitution experience with 31 consecutive patients. Clinical article. J Neurosurg Spine. 2009;11:3-8.

27. Emans JB, Caubet JF, Ordonez CL, et al. The treatment of spine and chest wall deformities with fused ribs by expansion thoracostomy and insertion of vertical expandable prosthetic titanium rib: growth of thoracic spine and improvement of lung volumes. Spine. 2005;30(suppl 17):S58-S68.

28. Campbell RM Jr, Hell-Vocke AK. Growth of the thoracic spine in congenital scoliosis after expansion thoracoplasty. J Bone Joint Surg Am. 2003;85-A:409-420.

29. Smith JT, Smith MS. Can infection associated with rib distraction techniques be managed without implant removal? Spine. 2001;36:2176-2179.

30. Sankar WN, Acevedo DC, Skaggs DL. Comparison of complications among growing spinal implants. Spine. 2010;35:2091-2096.

31. Caubet JF, Emans JB. Halo-gravity traction versus surgical release before implantation of expandable spinal devices: a comparison of results and complications in earlyonset spinal deformity. J Spinal Disord Tech. 2011;24:99-104.

32. Gadepalli SK, Hirschl RB, Tsai WC, et al. Vertical expandable prosthetic titanium rib device insertion: does it improve pulmonary function? J Pediatr Surg. 2011;46:77-80.

33. Shah SC, Birknes JK, Sagoo S, Thome S, Samdani AF. Vertical expandable prosthetic titanium rib (VEPTR): indications, technique, and management review. Surg Technol Int. 2009; 18:223-229.

34. Choi E, Yaszay B, Mundis G, et al. Implant complications after magnetically controlled growing rods for early onset scoliosis: a multicenter retrospective review. $J$ Pediatr Orthop. 2017;37(8):e588-e592.

35. Ridderbusch K, Rupprecht M, Kunkel P, Hagemann C, Stücker R. Preliminary results of magnetically controlled growing rods for early onset scoliosis. J Pediatr Orthop. 2017;37(8):e575-e580.

36. Lebon J, Batailler C, Wargny M, et al. Magnetically controlled growing rod in early onset scoliosis: a 30-case multicenter study. Eur Spine J. 2017;26(6):1567-1576.
37. Teoh KH, von Ruhland C, Evans SL, et al. Metallosis following implantation of magnetically controlled growing rods in the treatment of scoliosis: a case series. Bone Joint J. 2016;98B:1662-1667.

38. Sankar WN, Skaggs DL, Yazici M, et al. Lengthening of dual growing rods and the law of diminishing returns. Spine. 2011;36(10):806-809.

39. Noordeen HM, Shah SA, Elsebaie HB, et al. In vivo distraction force and length measurements of growing rods: which factors influence the ability to lengthen? Spine. 2011;36(26):2299-2303.

40. Vitale MG, Gomez JA, Matsumoto H, et al. Chest Wall and Spine Deformity Study Group. Variability of expert opinion in treatment of early-onset scoliosis. Clin Orthop Relat Res. 2011;469:1317-1322.

41. Wang S, Zhang J, Qiu G, et al. Dual growing rods technique for congenital scoliosis: more than 2 years outcomes: preliminary results of a single center. Spine. 2012;37:E1639E1644.

42. Gomez JA, Grzywna A, Hanstein R, et al. Staged growing rods with preimplantation of spinal anchors for complex early onset scoliosis. $J$ Pediatr Orthop. 2017;37(8):e606-e611. doi:10.1097/BPO.0000000000000957

43. Johnston CE. Preoperative medical and surgical planning for early onset scoliosis. Spine (Phila Pa 1976). 2010;35(25):2239-2244.

Disclosures and COI: The authors received no funding for this study and do not have any conflicts of interest to declare.

Corresponding Author: David Parsons, MD, FRCSC, Department of Surgery, Division of Pediatric Orthopaedic Surgery, Alberta Children's Hospital, University of Calgary, 2888 Shaganappi Trail Northwest, Calgary, AB, T3B 6A8, Canada. Phone: (403) 955-7730; Fax: (403) 955-2813; Email: david.parsons1@me.ca.

Published 16 April 2021

This manuscript is generously published free of charge by ISASS, the International Society for the Advancement of Spine Surgery. Copyright $\odot 2021$ ISASS. To see more or order reprints or permissions, see http://ijssurgery.com. 